\title{
A propósito de "Luz que Flota en el Olvido"
}

(Selección de sonetos colombianos arreglada por Carlos García-Prada)

$\mathbf{L}$

A empresa parecía temeraria. Hacer una compilación de sanetos debidos todos a autores colombianos de manera que palpitase en ellos una idea coherente, una virtud espiritual común, con cuyo prestigio esas composiciones imaginadas por talentos de tan varia sensibilidad y de conceptos tan divergentes frente a los grandes problemas de la vida, vinieran a formar algo así como el poema lírico del alma colombiana, tenía los caracteres de una batalla perdida antes de empezar la lucha.

Había, además, otro escollo: para que no fueran demasiado patentes las divergencias de forma era necesario buscar con criterio elevado piezas de un valor indudable, no sólo del punto de vista de la idea, sino también, y principalmente cuanto a la forma, por tratarse del "breve y amplísimo carmen" en que dejaron lo mejor de sus sentimientos Alighieri, Shakespeare, el hombre de las Luisiadas y en nuestros dias Foscolo, Baudelaire y Carducci. La lectura de la selección nos deja la dulce y sorpresiva convicción de que en este país, nobles espíritus, inteligencias distinguidas han dejado en forma de sonetos la ecuación de la sensibilidad nacional.

Casi toda la vida espiritual de cuatro generaciones aparece aquí proyectada sobre la pantalla de la poesía en forma no solamente atractiva y hermosa, sino principalmente histórica en el sentido de prodigioso recuento de nuestras aspiraciones, de nuestro modo de con- 
cebir la existencia, de nuestros duraderos pesares y de nuestras aparentes y efímeras alegrías.

Es verdad que no es obra del primer venido el arreglo de una selección como ésta. En García-Prada concurren por maravillosa disposición de las musas todas las cualidades requeridas para llevar a cabo obra de tantos quilates literarios y psicológicos. GarcíaPrada es un poeta, no en el estrecho sentido de que expresa bellamente sus sentimientos en cabos rimados, sino en el de su compenetración con el alma de las cos̀as y con el significado esotérico de esta exhalada sucesión de fenómenos que llamamos vida. Es, además, un esteta, es decir, un hombre que atisba las leyes de nuestra sensibilidad. Conoce nuestra poesía, la entiende y la adora con pasión refrenada sólo por el instinto de la belleza ínsito en su delicado espíritu. Por último, el amor a la patria, sublimado por la ausencia, le abría de par en par las puertas de ese magnífico acervo de recuerdos que es la vida nacional.

No creo que ningún otro país de América suministre una cantidad de poesía, expresada en sonetos, suficientemente copiosa para completar una selección tan abundante en piezas maestras y de tan hondo significado.

Ocurre, sin embargo, que hay poetas a quienes la forma del soneto deja de atraer con fascinaciones irresistibles y otros a quienes acaso les presenta su forma. No figura José A. Silva en esta selección: los acentos de su alma eran de naturaleza eruptiva, pero la firme elegancia de su espíritu le imponía la expresión en las formas menos evidentes y embarazadas. Su espiritu flota sobre el libro, como acongojado de que su alma no aparezca aquí en contacto con el espíritu de la patria. Fidel Cano, cuya vida forma parte de una época hermosa y doliente de la existencia total del país, fué poeta de hondas emociones y de forma severa $y$ hondamente personal. No figura en este libro porque no se expresó en sonetos su musa del hogar y de la naturaleza. Dejó uno, solamente, que aparecerá en el proceso de la historia contra cierto mandatario.

No todos los grandes poetas fueron cultores apasionados del soneto. No aparece uno solo en los cuatro volúmenes de versos labrados con el cincel con que trazaron los pliegues del manto de los dioses los escultores de Grecia. Apenas por su respeto a Baudelaire usó la forma del soneto en las insuperables traducciones de las 
Flores del alma con que enriqueció la lengua alemana. No están en sonetos los más bellos versos de Goethe.

Por último cabe una ligera observación. Entre los sonetistas del volumen la nota del humor colombiano está representada por dos sonetos del genialísimo Luis E. López y por uno o dos desahogos verbales en que el humor se subordina a la tristeza. ¿Es que la inteligencia colombiana es por naturaleza $y$ en grande abundancia triste? Es verdad que somos tristes, pero el humorismo no riñe con la melancolía de la vida interior. ¿Es que el soneto no se presta a las expansiones del buen humor? Importa leer a Pascarella en su "Scoperta dell America".

Carlos García-Prada ha levantado a Colombia un monumento de ladrillos babilónicos con inscripciones perfectamente legibles y además hermosas.

Baldomero Sanín Cano 
